\title{
Effect of Exterior Home Renovation on Community Lead Hazards: A Pilot Study in South
}

\section{Bend, Indiana}

Kyle J. Moon ${ }^{1}$; Meghanne E. Tighe, Ph.D. '; Joshua D. Brooks, B.B.A. ${ }^{2}$; J. Mike Coman, M.Ed., M.Div. ${ }^{3}$; Heidi Beidinger-Burnett, Ph.D., M.P.H. ; Matthew Sisk, Ph.D., ${ }^{4,5}$; Marya Lieberman, Ph.D. ${ }^{1}$

1. Department of Chemistry and Biochemistry, University of Notre Dame, Notre Dame, IN 46556

2. Office of Sustainability, University of Notre Dame, Notre Dame, IN 46556

3. Monroe Park Neighborhood Association, South Bend, IN 46601

4. Eck Institute for Global Health, University of Notre Dame, Notre Dame, IN 46556

5. Navari Family Center for Digital Scholarship, Hesburgh Libraries, University of Notre Dame, Notre Dame, IN 46556

\begin{abstract}
Communities across the US face challenges from legacy lead contamination. In South Bend, Indiana, over 68,000 homes were built before 1978, and most contain leaded paint. When these homes are repainted, repaired, or renovated, failure to use lead-safe practices can contaminate the surrounding soil with lead paint flakes and dust. In this study, we used X-ray fluorescence (XRF) to measure soil lead levels surrounding a home with exterior leaded paint (about $10 \% \mathrm{~Pb}$ w/w) after it was repainted in fall of 2019. The painted wooden exterior was prepared for painting by dry scraping without the use of tarps or plastic barriers. A total of 220 soil samples were collected from the home and its immediate neighbors, and an additional 102 samples were collected from 34 homes in the same neighborhood. The median lead level in dripline soil samples across the neighborhood was $434 \mathrm{ppm}$, but in the recently repainted house,
\end{abstract}


the median soil lead was $1808.9 \mathrm{ppm}$, and it was 1,346.4 ppm in the four neighboring homes. The repainted house and its four neighbors were mulched by covering all bare soil to a 4-6 inch depth with chipped wood mulch. Two months later, another 100 soil samples were collected and analyzed. The surface lead level around the target house dropped to $13.8 \mathrm{ppm}$, showing that mulching is an effective strategy for interim control of high soil lead levels.

\section{Introduction}

Soil constitutes a major source of lead exposure among young children, who often play in the soil and engage in hand-to-mouth behaviors. ${ }^{1-3}$ Soil lead results from either (a) historic use of leaded gasoline or (b) chipping lead-based paint on the exterior walls of the home. Consequently, lead remediation initiatives focus on controlling lead-based paint hazards, which is cost-effective, producing significant returns on investment and reductions in children's blood lead levels (BLLs)., ${ }^{4,5}$

Initiatives that seek to address soil as the principal source of lead exposure have produced indeterminate results, however. ${ }^{6}$ In the 1980s, the Environmental Protection Agency (EPA) funded studies on soil lead abatement in 3 cities: Boston, Baltimore, and Cincinnati. In Boston, researchers found that soil lead abatement, or removal, was associated with statistically significant reductions in children's BLLs, ${ }^{7}$ while researchers concluded that, in Baltimore, soil lead abatement had no effect on children's BLLs. ${ }^{8}$ These studies evaluated the the impacts of abatement practices designed to remove lead from the home environment. However, many homes are painted by do-it-yourself home residents or neighborhood painters who do not use known best practices (cite RRP program) such as enclosing the work area, laying down plastic to 
catch paint chips/dust, and using wet scraping or HEPA-filtered sanding equipment. In this case study, we evaluated the neighborhood impact of exterior repainting that was conducted without efforts to contain the spread of paint chips and dust.

Environmental lead hazards are of particular concern in South Bend, Indiana, where an estimated $80 \%$ of homes were built before 1978 , when lead-based paint was banned by the U.S. government for residential use. In this manuscript, we present a case study of environmental lead hazards in Monroe Park, one of South Bend's oldest neighborhoods, built in 1890. Racial and ethnic minorities constitute half of the neighborhood population, and it ranks among South Bend's most economically disadvantaged neighborhoods. ${ }^{10}$ These characteristics can be traced to practices of redlining, where Monroe Park-like other neighborhoods of color-was deemed a "hazardous" investment for banks (Figure 1).

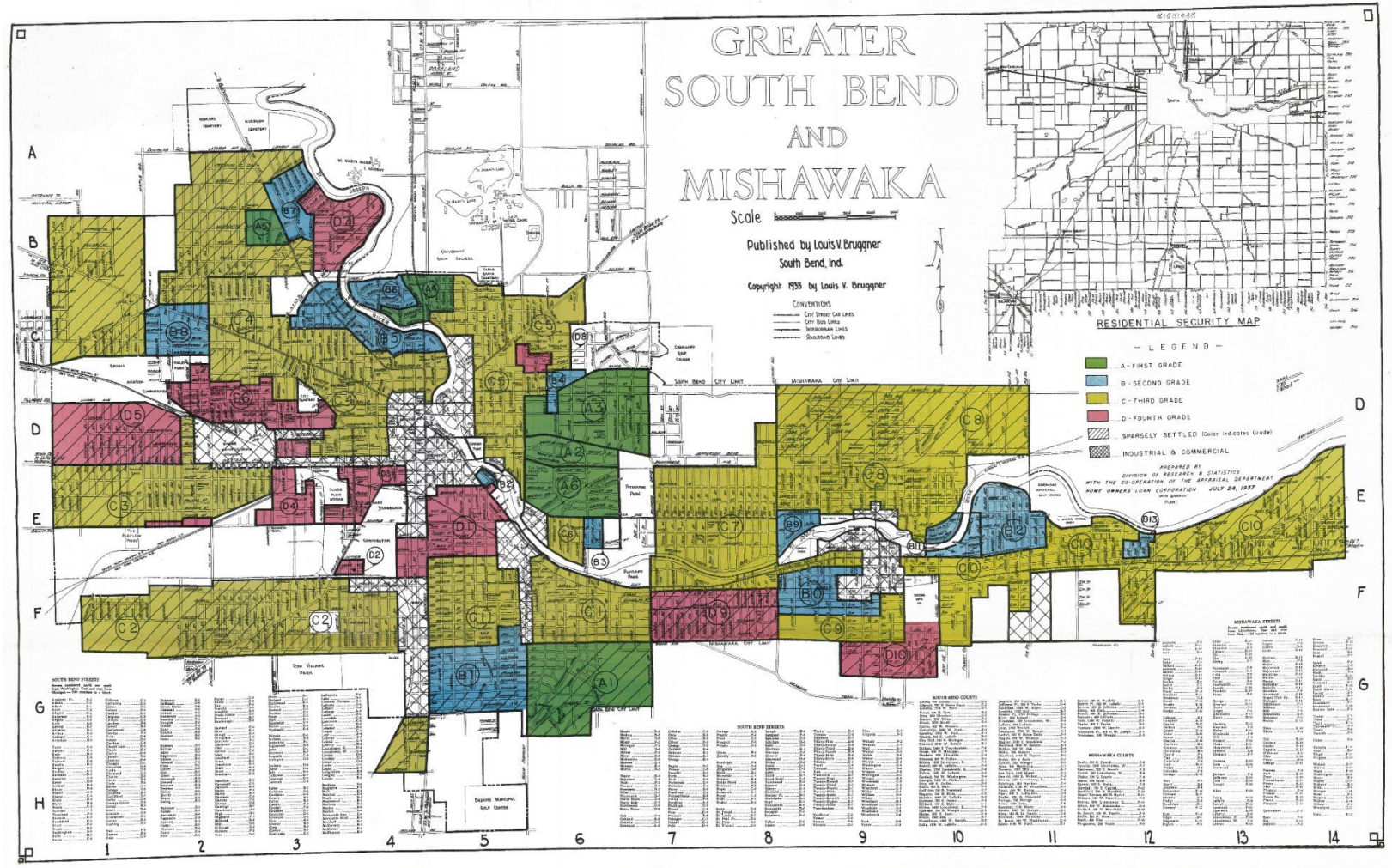


Figure 1. Redlining map of South Bend, Indiana. Monroe Park is color-coded red (D1), which corresponds to a neighborhood that poses "hazardous" risk to banks and other mortgage lenders. ${ }^{11}$

\section{Methods}

\section{Sample Collection}

In fall 2019, a local contractor prepared the exterior of a community-based organization located in the Monroe Park neighborhood for repainting by dry scraping without the use of tarps to collect paint chips. Weeks after renovation, volunteers hand-collected paint chips that had deposited in the soil and yard. At the recently renovated community-based organization, five paint samples were collected, along with 100 soil samples from the dripline, followed by a soil grid analysis, with 80 samples collected at the following distances from the exterior wall of the home: $1 \mathrm{ft}, 2 \mathrm{ft}, 3 \mathrm{ft}, 4 \mathrm{ft}, 5 \mathrm{ft}, 10 \mathrm{ft}$, and $20 \mathrm{ft}$. A 4-6" coat of mulch was applied at the recently renovated home, and two months after mulching, an additional 100 soil samples were collected from the dripline to assess the effect of mulching on lead concentration at the surface. A total of 40 soil sample samples were obtained from the driplines of four neighboring houses (two homes on each side of the community-based organization). Soil samples were collected from 34 additional homes in the neighborhood, with three samples taken at each home. All samples were analyzed with a Sciaps X-100 portable x-ray fluorescence (pXRF) spectrometer.

\section{Statistical Analysis}

Data from the soil grid analysis were assessed with a Kruskal-Wallis test after results from the Levene test indicated unequal variance, meaning the assumptions of a one-way analysis of variance (ANOVA) were violated. The Kruskal-Wallis test was used to identify if there were 
any differences in soil $\mathrm{Pb}$ concentration as a function of distance from the home, ${ }^{12}$ and Dunn's test with Bonferroni correction was used for multiple comparisons. ${ }^{13}$ To assess differences in soil lead concentration between neighbors of the recently renovated community-based organization and other homes in the neighborhood, Mann-Whitney U test was used. ${ }^{14}$ To assess differences in soil lead concentration before and after mulching, Wilcoxon signed-rank test was used after the Shapiro-Wilk test indicated data were not normally distributed $(\mathrm{P}<0.001)$.

\section{Results}

Soil Grid Analysis

Analysis by pXRF revealed the paint chips collected from the community-based organization site to be $11.0 \pm 3.8 \%$ lead $(\mathrm{Pb})$ by weight, as shown in Table 1 . The exterior repainting of this building resulted in serious lead contamination of soil as far as 15 feet from the exterior walls of the building (Figure 2), which is the average distance between homes in the neighborhood, and even extended past the property line in some directions (Figure 3). Average soil lead concentration was elevated ( $\geq 400 \mathrm{ppm}$ ) at all locations except for samples $20 \mathrm{ft}$ from the exterior wall of the house. Soil $\mathrm{Pb}$ concentration differed significantly as a function of distance (Figure 2), with significant differences identified between samples at $20 \mathrm{ft}$ from the home and all other locations, except $1 \mathrm{ft}$ and $2 \mathrm{ft}$ from the home, where the differences were marginally significant $(\mathrm{P}=0.053$ and $\mathrm{P}=0.083$, respectively $)$.

Table 1. Analysis of Lead Content in Paint Chips with pXRF.

\begin{tabular}{|l|l|l|l|l|l|l|r|}
\hline \multicolumn{1}{|c|}{ Measurement } & Sample 1 & Sample 2 & Sample 3 & Sample 4 & Sample 5 & Average & Standard Deviation \\
\hline $\begin{array}{l}\text { Lead Concentration } \\
\text { (ppm) }\end{array}$ & $170,196.6$ & $76,484.7$ & $94,124.8$ & $84,373.2$ & $124,415.6$ & $109,919.0$ & $38,286.5$ \\
\hline
\end{tabular}




\begin{tabular}{|l|r|r|r|r|r|r|r|}
\hline $\begin{array}{l}\text { Lead Percent by } \\
\text { Weight (\%) }\end{array}$ & $17.0 \%$ & $7.6 \%$ & $9.4 \%$ & $8.4 \%$ & $12.4 \%$ & $11.0 \%$ & $3.8 \%$ \\
\hline
\end{tabular}

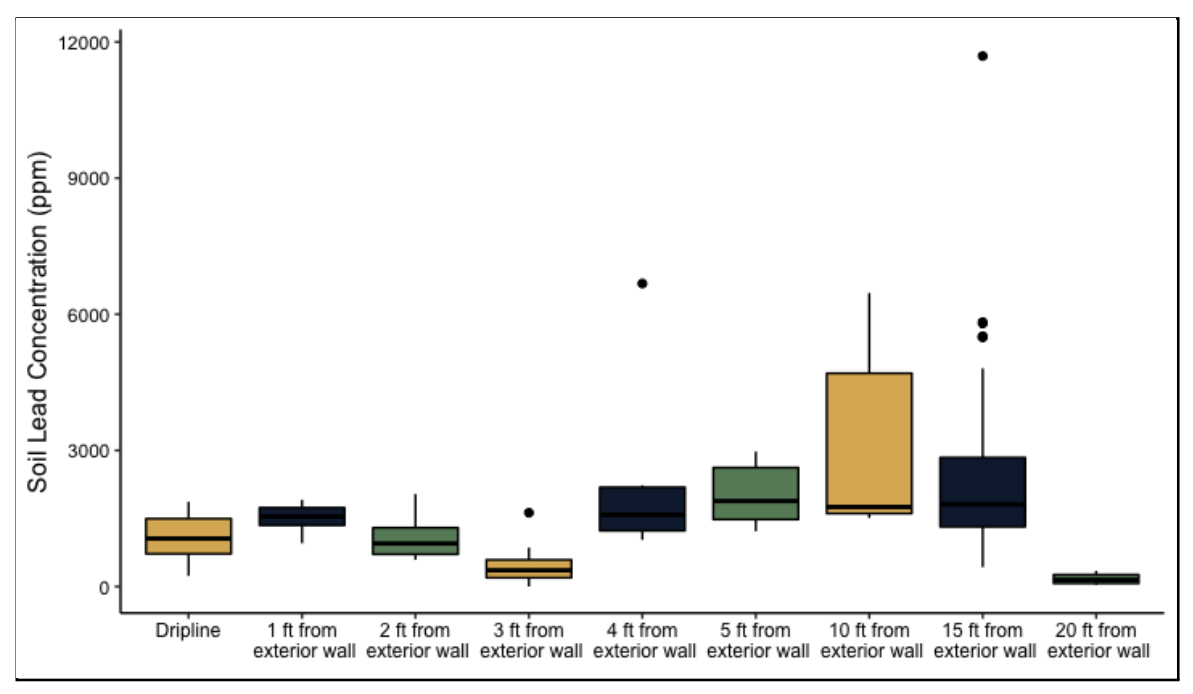

Figure 2. Soil $\mathrm{Pb}$ concentration as a function of distance from the exterior wall of the home. Soil $\mathrm{Pb}$ concentration $20 \mathrm{ft}$ from the home differed significantly $(\mathrm{P}<0.05)$ from samples at all other locations, except $1 \mathrm{ft}(\mathrm{P}=0.053)$ and $2 \mathrm{ft}(\mathrm{P}=0.083)$ from the home. 


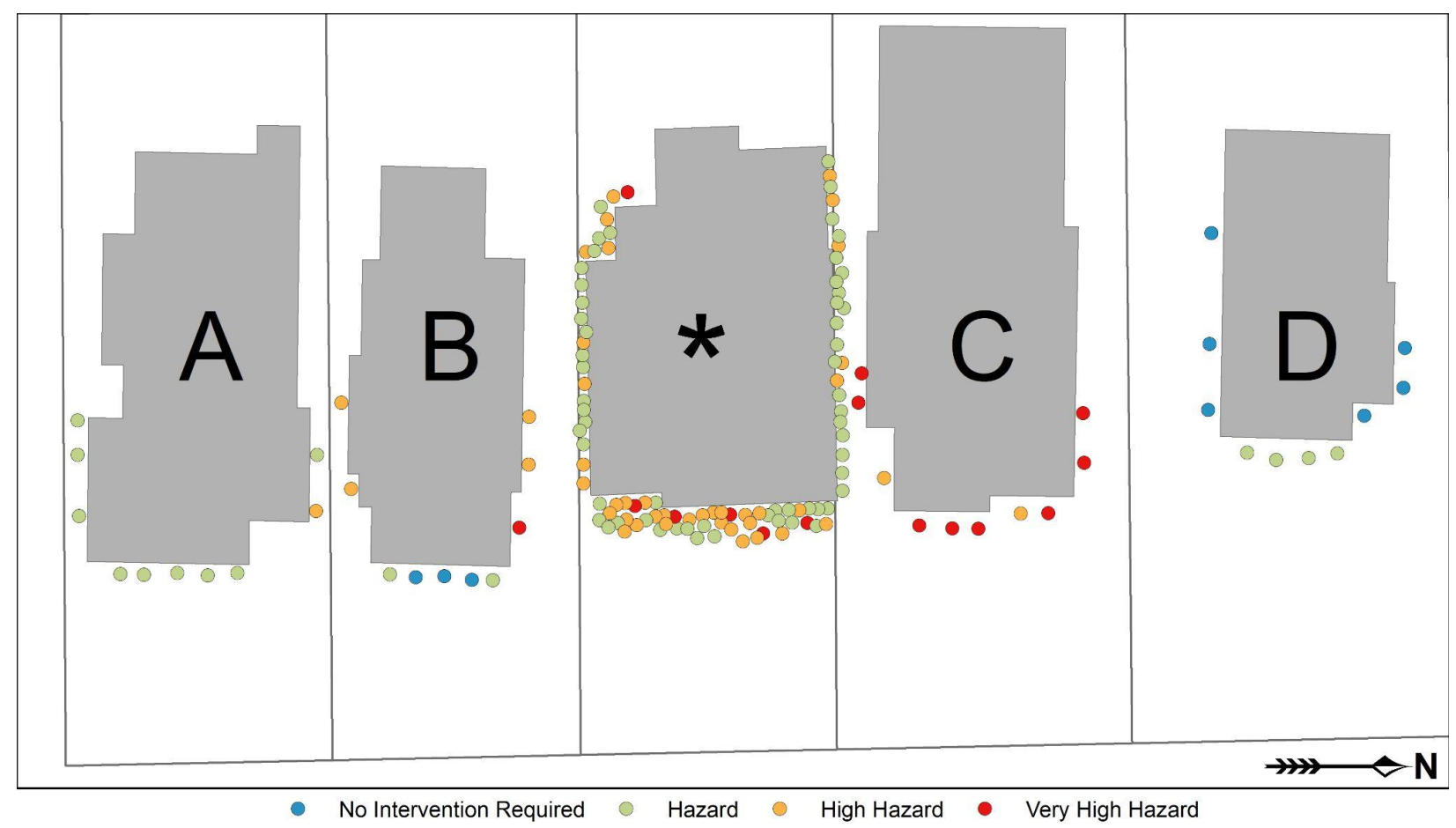

Figure 3. Community lead burden after exterior renovation. Shown is a map of the five pilot homes, where the community-based organization is indicated with an asterisk. Point locations are only accurate to the side of the building (front or side dripline; coordinates were not collected), and are color-coded according to $\mathrm{Pb}$ hazard level: no intervention required $(<400 \mathrm{ppm} \mathrm{Pb})$, hazard (400-2,000 ppm Pb), high hazard (2,000-5,000 ppm $\mathrm{Pb})$, and very high hazard $(\geq 5,000$ ppm $\mathrm{Pb})$.

\section{Effect of Renovation on Surrounding Homes}

While we lack baseline soil samples to assess the impact of renovation on the pilot home and neighboring homes, a significant number of paint chips were found throughout the yard and yards of neighboring homes, requiring collection of paint chips by hand for safe disposal.

Because of the age of the neighborhood, widespread environmental lead hazards are expected, including elevated soil lead concentrations. To assess the potential contribution of the exterior 
home renovation to the community lead burden, we compared the soil lead concentration of the four neighboring homes participating in this pilot study to thirty-four additional homes in the Monroe Park neighborhood. As expected, soil lead concentration was high throughout the neighborhood, with a median soil lead concentration of $434.0 \mathrm{ppm}$ among the 34 homes sampled, but soil lead concentration was significantly higher $(\mathrm{P}<0.001)$ among the four neighboring homes of the renovated community-based organization, with a median soil lead concentration of 1,346.4 ppm (Figure 4).

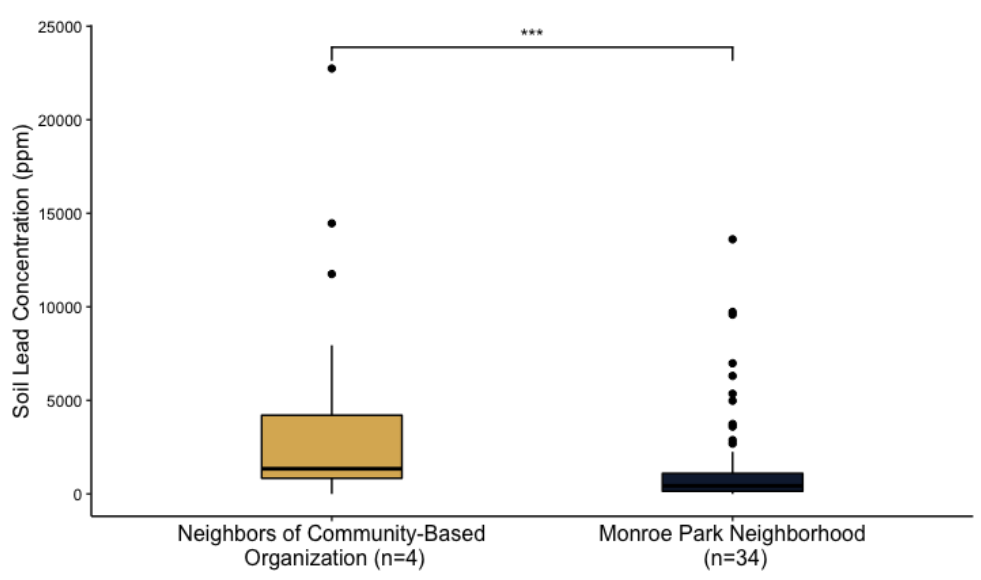

Figure 4. Soil $\mathrm{Pb}$ hazards throughout the Monroe Park neighborhood. While soil $\mathrm{Pb}$ levels were elevated throughout the Monroe Park neighborhood (median $=434.0 \mathrm{ppm}, \mathrm{n}=34$ ), soil $\mathrm{Pb}$ concentration was significantly higher $(\mathrm{P}<0.001)$ among the four neighboring homes of the community-based organization (median $=1,346.4 \mathrm{ppm}$ ) following its renovation. Statistical significance was assessed with the Mann-Whitney U test. 
An initial round of mulching at the community-based organization's home building reduced the median lead concentration from 1,808.9 ppm to $13.8 \mathrm{ppm}$ (Figure S5), which inspired local community organizers and volunteer groups to attempt a larger scale mulching project in the neighborhood.

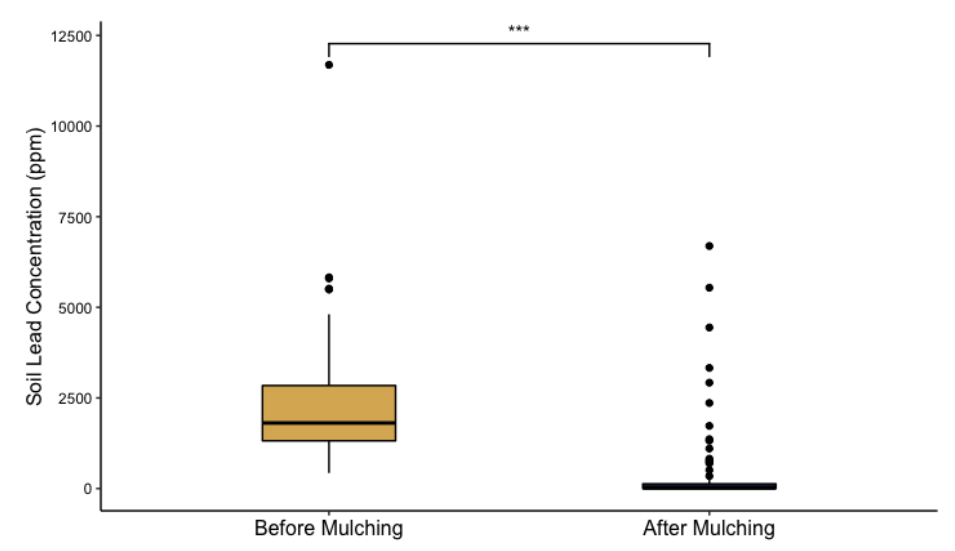

Figure 5. Soil lead concentration before and one month after mulching at the community-based organization. The median soil lead concentration was 1,808.9 ppm before mulching and 13.8 ppm one month after mulching. Statistical significance was assessed with Wilcoxon signed-rank test $(\mathrm{P}<0.001)$. This intervention was executed in fall 2019, and the results informed neighborhood-wide remediation efforts undertaken in 2021.

\section{Discussion}

While soil lead hazards were widespread throughout the Monroe Park neighborhood, soil at the four neighboring homes was significantly higher $(\mathrm{P}<0.001)$, as shown in Figure 4, which suggests that exterior home renovations that do not adhere to EPA recommendations for renovation, repair, and repainting may contribute to the community lead burden. ${ }^{15-17}$ 
Existing studies have shown that mulching, as a remediation strategy, can significantly reduce soil lead concentration at the surface, where children might be exposed. ${ }^{3,9}$ Although a pilot study, findings from this project add to existing evidence of mulching as a cost-effective strategy for remediating environmental lead hazards, ${ }^{27}$ considering the tangible benefits to residents of the neighborhood, with no net costs to the research team or neighborhood association. Moreover, this study provides further evidence of the potential of community-academic partnerships in developing actionable interventions to respond to environmental health hazards. ${ }^{28,29}$ These partnerships make use of academic institutions' resources-namely, faculty expertise, research facilities, and student volunteers-and depend on the local expertise of community members for effective implementation. ${ }^{29}$ To ensure successful partnerships, community organizations must be equal partners in design and implementation, and results must be shared with the community in a timely and accessible manner. ${ }^{28,29}$ After disseminating findings with community members, academic institutions should continue to sustain their partnership, establishing trust with community members.

Mulching is a short-term remediation and will need to be reapplied in the future, providing a natural opportunity to sustain this community-academic partnership. Longitudinal studies should be pursued, with routine monitoring of soil lead levels after an intervention, to inform guidance on when mulch must be re-applied (e.g., annually).

To respond to environmental lead hazards, residents were made aware of lead screening kits to detect lead in dust, soil, paint, and water, identifying hazards before a child receives an elevated blood lead test. ${ }^{18,22}$ Kit distribution presents a challenge, however, because homeowners who know that their home has lead-based paint are required to disclose this information when selling or renting. ${ }^{30}$ Because the disclosure of lead-based paint may negatively impact home 
value, individuals may be discouraged from completing lead screening kits that serve as prevention tools in identifying hazards before a child receives an elevated blood lead test.

One noteworthy limitation of our findings relates to scientific consensus on what constitutes a soil lead hazard. While mulching effectively reduced the soil $\mathrm{Pb}$ concentration to levels below the hazard threshold of $400 \mathrm{ppm} \mathrm{Pb}$, many have challenged existing guidelines of what constitutes a hazard, calling upon the EPA to lower the soil lead hazard threshold. ${ }^{6,31}$ Existing literature, however, suggests that soil lead abatement (1) is too costly for the associated benefit and (2) has little impact on leaded dust inside the home, ${ }^{7}$ calling instead for interventions that make housing lead-safe. ${ }^{2}$

\section{References}

1. Filippelli GM, Laidlaw MAS. The elephant in the playground: confronting lead-contaminated soils as an important source of lead burdens to urban populations. Perspect Biol Med. 2010;53(1):31-45. doi:10.1353/pbm.0.0136.

2. Ryan D, Levy B, Pollack S, Walker B. Protecting children from lead poisoning and building healthy communities. Am J Public Health. 1999;89(6):822-24. doi:10.2105/AJPH.89.6.822.

3. Nielsen JB, Kristiansen J. Remediation of soil from lead-contaminated kindergartens reduces the amount of lead adhering to children's hands. J Expo Sci Environ Epidemiol. 2005;15:282-88. doi:10.1038/sj.jea.7500403.

4. Gould E. Childhood lead poisoning: Conservative estimates of the social and economic benefits of lead hazard control. Environ Health Perspect. 2009;117(7):1162-67. doi:10.1289/ehp.0800408. 
5. Clark S, Galke W, Succop P, Grote J, McLaine P, Wilson J, Dixon S, Menrath W, Roda S, Chen M, Bornschein R, Jacobs D. Effects of HUD-supported lead hazard control interventions in housing on children's blood lead. Environ Res. 2011;111(2):301-11. doi:10.1016/j.envres.2010.11.003.

6. Laidlaw MAS, Filippelli GM, Brown S, Paz-Ferreiro J, Reichman SM, Netherway P, Truskewycz A, Ball AS, Mielke HW. Case studies and evidence-based approaches to addressing urban soil lead contamination. Appl Geochem. 2017;83:14-30. doi:10.1016/j.apgeochem.2017.02.015.

7. Aschengrau A, Beiser A, Bellinger D, Copenhafer D, Weitzman M. The impact of soil lead abatement on urban children's blood lead levels: Phase II results from the Boston lead-in-soil demonstration project. Environ Res. 1999;67(2):125-48. doi:10.1006/enrs.1994.1069.

8. Farrell KP, Brophy MC, Chisholm JJ, Rohde CA, Strauss WJ. Soil lead abatement and children's blood lead levels in an urban setting. Am J Public Health. 1998;88(12):1837-39. doi:10.2105/AJPH.88.12.1837.

9. Dixon SL, McLaine P, Kawecki C, Maxfield R, Duran S, Hynes P, Plant T. The effectiveness of low-cost soil treatments to reduce soil and dust lead hazards: The Boston lead safe yards low cost lead in soil treatment, demonstration, and evaluation. Environ Res. 2006;102(1):113-24. doi:10.1016/j.envres.2006.01.006.

10. U.S. Census Bureau. Overview of Monroe Park, South Bend, Indiana. Statistical Atlas. https://statisticalatlas.com/neighborhood/Indiana/South-Bend/Monroe-Park/Overview. Published September 14, 2008. Accessed June 28, 2021. 
11. Nelson RK, Winling L, Marciano R, Connolly N, Ayers EL. Mapping inequality. American Panorama. https://dsl.richmond.edu/panorama/redlining/. Published December 2015. Accessed June 28, 2021.

12. McKight PE, Najab J. Kruskal-Wallis test. In: Weiner IB, Craighead WE, eds. The Corsini Encyclopedia of Psychology. Wiley; 2010. doi:10.1002/9780470479216.corpsy0491.

13. Dinno A. Nonparametric pairwise multiple comparisons in independent groups using Dunn's test. Stata J. 2015;15(1):292-300. doi:10.1177/1536867X1501500117.

14. MacFarland TW, Yates JM. In: Introduction to Nonparametric Statistics for the Biological Sciences Using R. Springer; 2016: pp. 103-32. doi:10.1007/978-3-319-30634-6_4.

15. U.S. EPA. Lead renovation, repair, and painting program. https://www.epa.gov/lead/ lead-renovation-repair-and-painting-program. Published October 15, 2020. Accessed June 30, 2021.

16. Mielke HW, Powell ET, Shah A, Gonzales CR, Mielke PW. Multiple metal contamination from house paints: consequences of power sanding and paint scraping in New Orleans. Environ Health Perspect. 2001;109(9):973-78. doi:10.1289/ehp.01109973.

17. Sussell A. An evaluation of worker lead exposures and cleaning effectiveness during removal of deteriorated lead-based paint. Appl Occup Environ Hyg. 1999;14(3):177-85. doi:10.1080/104732299303142.

18. Tighe M, Knaub C, Sisk M, Ngai M, Lieberman M, Peaslee G, Beidinger H. Validation of a screening kit to identify environmental lead hazards. Environ Res. 2020;181:108892. doi:10.1016/j.envres.2019.108892. 
19. U.S. EPA. Hazard Standards and Clearance Levels for Lead in Paint, Dust and Soil (TSCA Sections 402 and 403). https://www.epa.gov/lead/ hazard-standards-and-clearance-levels-lead-paint-dust-and-soil-tsca-sections-402-and-40 3. Published January 7, 2021. Accessed August 2, 2021.

20. Centers for Disease Control and Prevention. Exposure to Lead can Seriously Harm a Child's Health Infographic. https://www.cdc.gov/nceh/lead/prevention/ infographic-lead-exposure.htm. Published October 7, 2020. Accessed March 25, 2021.

21. Bauer C. South Bend gets $\$ 2.3$ million federal grant to fight lead hazards. South Bend Tribune. December 20, 2018. Accessed June 30, 2021. https://www.southbendtribune.com/news/local/south-bend-gets-2-3million-federal-grant-to-fight-lead-hazards/article_85d9dea0-b910-5588-8940-6228149f8 fb6.html? redir $=0$.

22. Tighe M, Bielski M, Wilson M, Ruscio-Atkinson G, Peaslee GF, Lieberman M. A sensitive XRF screening method for lead in drinking water. Anal Chem. 2020;92:4949-53. doi:10.1021/acs.analchem.9b05058.

23. U.S. EPA. Lead regulations: lead in paint, dust, and soil. https://www.epa.gov/sites/production/files/2020-10/documents/lead-in-soil-aug2020.pdf. Published June 16, 2021. Accessed June 29, 2021.

24. Renner R. Exposure on tap: Drinking water as an overlooked source of lead. Environ Health Perspect. 2010;118(2):69-74. doi:10.1289/ehp.118-a68.

25. Woolson RF. Wilcoxon signed-rank test. In: D’Agostino RB, Sullivan L, Massaro J, eds. Wiley Encyclopedia of Clinical Trials. Wiley; 2008. doi:10.1002/9780471462422.eoct979. 
26. Leon AC. Descriptive and inferential statistics. In: Bellack AS, Hersen M, eds. Comprehensive Clinical Psychology. Pergamon Press; 1998: 282. doi:10.1016/B0080-4270(73)00264-9.

27. Mielke HW, Powell ET, Gonzales CR, Mielke PW, Ottesen RT, Langedal M. New Orleans soil lead $(\mathrm{Pb})$ cleanup using Mississippi River alluvium: Need, feasibility, and cost. Environ Sci Technol. 2006;40(8):2784-89. doi:10.1021/ es0525253.

28. Carney JK, Maltby HJ, Mackin KA, Maksym ME. Community-academic partnerships: how can communities benefit? Am J Prev Med. 2011;41(4):S206-13. doi:10.1016/j.amepre.2011.05.020.

29. Israel BA, Schulz AJ, Parker EA, Becker AB. Community-based participatory research: Policy recommendations for promoting a partnership approach in health research. Educ Health. 2001;14(2):182-97. doi:10.1080/13576280110051055.

30. Residential Lead-Based Paint Hazard Reduction Act of 1992. Pub. L. 102-550, title X, $\S 1002$, Oct. 28, 1992, 106 Stat. 3672. https://www.epa.gov/lead/residential-lead-based-paint-hazard-reduction- act-1992-title-X.

31. Zahran S, Mielke HW, Weiler S, Gonzales CR. Nonlinear associations between blood lead in children, age of child, and quantity of soil lead in metropolitan New Orleans. Sci Total Environ. 2011;409(7):1211-18. doi:10.1016/ j.scitotenv.2010.11.036. 